\title{
Research on forming force of flexible rolling for three-dimensional surface sheet metal parts through numerical simulation
}

\author{
Fengyan Lun ${ }^{1,2, a}$, Wenzhi $\mathrm{Fu}^{1,{ }^{*}, \mathrm{~b}}$, Mingzhe $\mathrm{Li}^{1, \mathrm{c}}$ and Xintong Wang ${ }^{1, \mathrm{~d}}$ \\ ${ }^{1}$ Dieless Forming Technology Center, Jilin University, Changchun 130025, China; \\ ${ }^{2}$ College of Mechanical Engineering, Beihua University, Jilin 132021, China. \\ alfymore123@163.com, bfwz88@jlu.edu.cn, 'limz9@jlu.edu.cn, 'wxt870@sina.com \\ *Corresponding author
}

Keywords: Three-dimensional surface, flexible rolling, forming force, numerical simulation.

\begin{abstract}
Flexible rolling is a novel manufacturing technique for forming three-dimensional surface sheet metal parts. The working parts are two bendable rolls. The shape of each working roll can be adjustable respectively, and the gap of two rolls is controlled. The transverse curvature of the formed surface is the same as the curvature of the neutral layer of the gap. The longitudinal curvature of the formed surface is determined by non-uniform rolls gap which leads to non-uniform fiber extension. In this paper, the forming principle of the flexible rolling has been elaborated. The forming force characteristic has been analyzed. The modeling method has been described. The simulation results of the forming force have been analyzed. The forming experiment has been taken and the forming force has been tested. The correctness of the model and the simulation method has been verified. The research results show that the flexible rolling is a novel and effective method for forming three-dimensional surface sheet metal parts. The simulation method can deal with the difficulties of forming force calculation of flexible rolling effectively.
\end{abstract}

\section{Introduction}

Three-dimensional surface sheet metal parts are widely used in civilian and military field. For the three-dimensional surface parts, conventional die stamping is an effective approach. However, multi-varieties and small batch manufacturing represent the future direction of advantage manufacturing mode and has become the hot spot in the field of manufacturing research. In order to meet such requirements, a number of flexible forming methods have been proposed such as incremental forming and continuous roll forming [1, 2]. In order to manufacture 3D sheet metal parts fast and efficiently, Li and his co-workers put forward a novel forming process, namely flexible rolling [3]. This process combines the advantages of multi-point adjusting with the conventional rolling and inherits the flexibility of line forming and the continuous bending deformation. This method employs only two working rolls and the device is simpler and easier to operate.

Forming force is one of the most important process parameters of flexible rolling. Different from the calculation method of the forming force of traditional rolling [4], the bendable rolls are applied as the forming tool in flexible rolling, the forming force of flexible rolling is not just rolling force, but includes the bending force. These two forces are produced at the same time and have interactive effects. If the forming force need be calculated theoretically, the bending force and rolling force should be calculated respectively, and the total theoretical formed force is the sum of the bending force and rolling force. However, this simplification removed the mutual influence between bending force and rolling force, forming process does not conform to the actual. For the bendable working roll, the contact situation of roll and sheet is very complex. The influence factors of the forming force are many, so it is difficult to accurately calculate the forming force theoretically. Even if not consider these issues, analytic method only calculates the forming force of regular shape parts, such as forming spherical part. If forming complex curved surface, the contact shape of working roll and sheet metal is irregular and very complex. The horizontal projection area of the contact surface between the rolls and the sheet metal is difficult to work out, so the forming force is difficult to calculate. Aim of this 
paper is to study the feasibility and practicability by using simulation methods to realize the forming force calculation.

\section{The forming principle of three-dimensional surface and the forming process of flexible rolling}

Two bendable rolls are main working parts of flexible rolling forming equipment, as shown in Fig. 1. In the forming process, the shapes of upper and lower rolls are controlled by the adjusting units, respectively. As shown in Fig. 1(b), R1 and R2 are the bending radii of the centerline of the upper and lower roll. Adjusting the distance of two rolls, non-uniform roll gap is obtained.

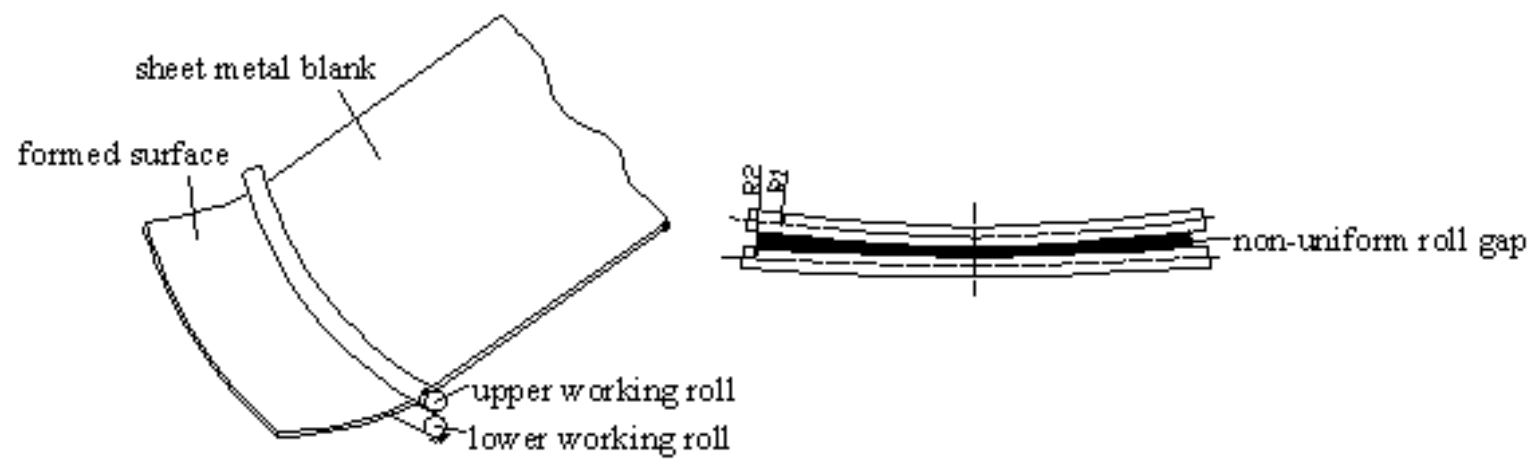

(a)

(b)

Fig. 1 The principle of flexible rolling (a) Forming process (b) Transverse cross section

As shown in Fig. 1(a), feed the sheet metal blank into the gap, then press down the upper roll. Further, two rolls were driven to rotate. Due to the friction force, the sheet moves forward continuously. Finally, three-dimensional surface parts are achieved.

When upper roll press down, the upper and lower rolls force the sheet blank to produce a certain bending deformation in transverse direction, as shown in Fig. 1(b). When the sheet metal feeds from one end of the roll gap to the other, it is compressed in the deforming region by the rolls. Plastic deformation happens in this process. Non-uniform reduction can be received in deforming region in the thickness direction owing to non-uniform gap. Since the volume of the forming sheet is constant and the width extension is little, the non-uniform reduction leads to non-uniform extensions in the rolling direction, i.e., the longitudinal direction. The extensions in this direction are different line by line. Due to the interconnected between the fibers of the metal, the superimposed stress is produced. The stress makes the sheet bend in the longitudinal direction. The bends in both directions occur simultaneously in the forming process. Three-dimensional surface is formed.

\section{Finite element model establishment and forming force simulation}

In order to research the forming force, the analysis software ABAQUS is applied to simulate flexible rolling process. In reality, the working roll is whole and bendable. It can rotate around itself bended axis. In order to simulate this kind of situation, the whole working roll is replaced with 21 short rolls in the model. 21 short rolls arranged according with the bended axis of the whole working roll, and each short roll can rotate around its own straight axis. The diameter of the short roll is $5 \mathrm{~mm}$, and the length of the short roll is $6 \mathrm{~mm}$. The size of sheet metal blank is $160 \mathrm{~mm} \times 120 \mathrm{~mm} \times 1 \mathrm{~mm}$. It is meshed with C3D8I element. The size of element is $1 \mathrm{~mm} \times 1 \mathrm{~mm} \times 0.5 \mathrm{~mm}$. The short rolls are meshed with R3D4 element, the mesh size is $0.3 \mathrm{~mm}$. the friction coefficient of the sheet metal and rolls is 0.2 . The material of the blank is $08 \mathrm{AL}$, density $\rho=7800 \mathrm{~kg} / \mathrm{m} 3$, elastic modulus $\mathrm{E}=206 \mathrm{GPa}$, and poisson's ratio $v=0.3$. The uniaxial stress-strain curve was obtained by tensile test, as shown in Fig. 2.

In order to study the forming force, spherical part is chosen as the research object. Target curvature of the part is $\mathrm{R}=500 \mathrm{~mm}$. According to the principle of flexible rolling, when forming the spherical parts, the reduction in the middle is biggest, while the reduction on both sides is zero. 
According to the formula, curvatures of two rolls which have been adjusted can be calculated. The curvature of the upper roll is $R_{1}=495 \mathrm{~mm}$. The curvature of the lower roll is $R_{2}=505 \mathrm{~mm}$. The maximum reduction in the middle is $0.03 \mathrm{~mm}$. On the basis of the data above, the finite element model of forming spherical surface is established, as shown in Fig. 3. The simulation result of the spherical part is shown in Fig. 4.

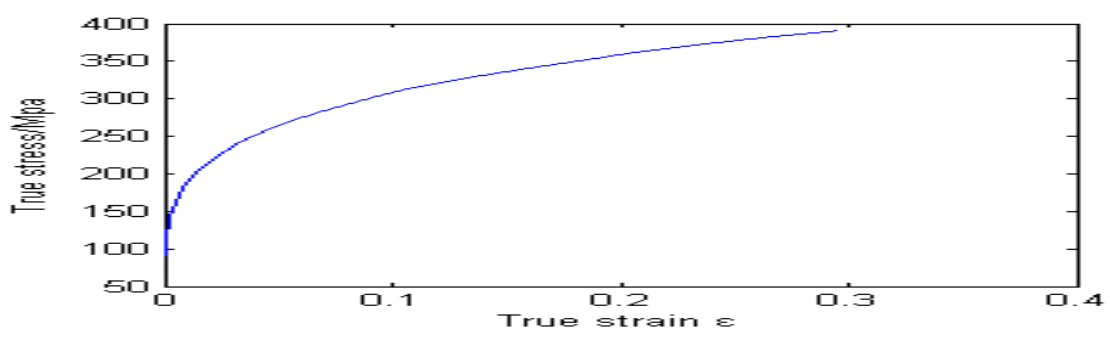

Fig. 2 stress-strain curve of 08AL

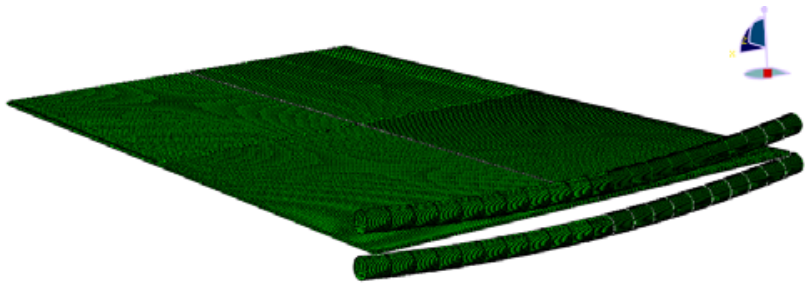

Fig. 3 The finite element model

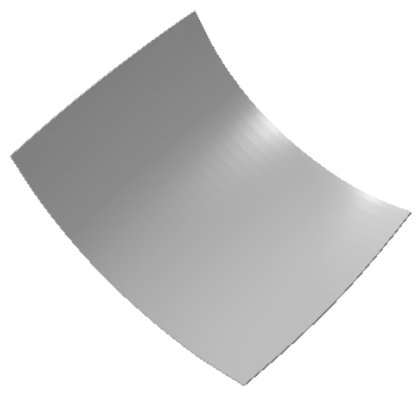

Fig. 4 Numerical simulation result

of the spherical part

Draw out the data of the magnitude forming force in post-processing module. The changing situation of the magnitude forming force is shown in Fig. 5.

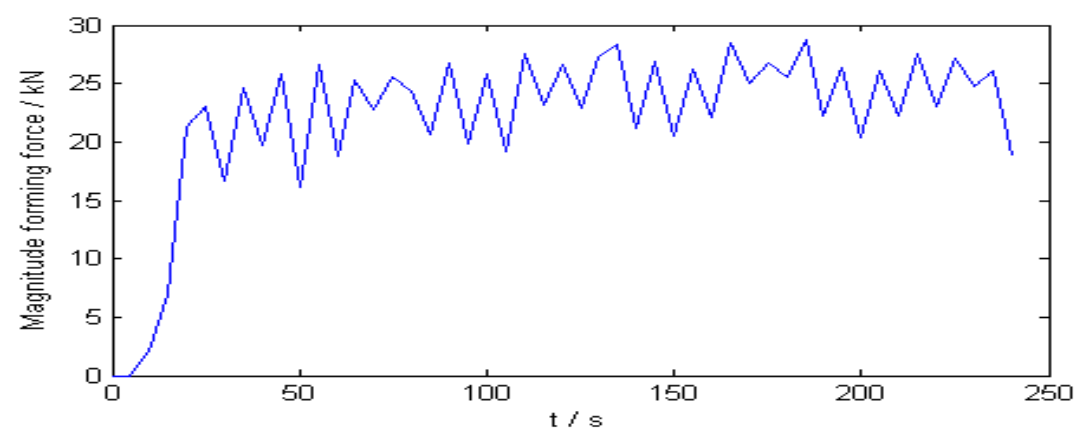

Fig. 5 Magnitude forming force of flexible rolling

From the figure, we know that the maximum forming force is $28.46 \mathrm{kN}$. In the forming process, it is not constant and has obvious fluctuation. This force fluctuates around one value. This is because of the plastic flow of the metal material is not enough homogeneous in the metal pressure processing. In the forming process, the sheet metal continuous bending in the transverse direction, compression in thickness direction and extension in longitudinal direction, the plastic flow of material occurred in each direction. Therefore, the inhomogeneous plastic flow is inevitable. This is the reason why fluctuation of the forming force appears. But the inhomogeneous plastic flow of the material only exists in the local. See from the whole forming process, plastic flow of the sheet metal is relatively stable and the fluctuation of the forming force is in the normal range.

\section{The forming force test and contrast}

The experimental device of the flexible rolling has been developed. The device is shown in Fig. 6 . The diameter of upper and down working rolls is $5 \mathrm{~mm}$. The shape and curvature of two rolls can be 
adjusted by ten control units respectively. The blank size is $160 \mathrm{~mm} \times 120 \mathrm{~mm} \times 1 \mathrm{~mm}$. Material is $08 \mathrm{Al}$. The target curvature of forming part is $\mathrm{R}=500 \mathrm{~mm}$.

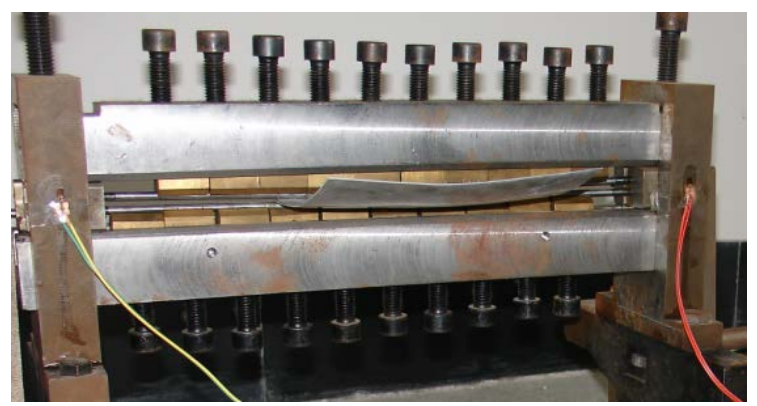

Fig. 6 Forming force test device

The forming force has been tested through XL 2101A Static Strain Gauge in forming process. The column material is 45 steel. The elastic module E=210Gpa. The column's cross section area is $\mathrm{A}=420 \mathrm{~mm}^{2}$. The maximum measured strain is $e=158 \mathrm{me}$. The maximum forming force can be calculated by Eq. (1).

$F=2 A E e=27.87 \mathrm{kN}$

The maximum forming force obtained by numerical simulation is $28.46 \mathrm{kN}$. The maximum forming force obtained by testing is $27.87 \mathrm{kN}$. The experimental value and the simulation one are on the same order of magnitude and the difference is small. The finite element method considers the problems of the working rolls pressing down, rotation and the contact with the sheet metal, material's strain hardening and inertia, etc., so it is closer to the actual situation. According to the analysis above, it is can be seen that the simulation value is similar to the test value. It shows the correctness of numerical simulation of the forming force.

\section{Conclusions}

1) The flexible rolling technology is a novel method for forming three-dimensional surface sheet metal parts rapid and continuous, which combined with bending and rolling process.

2) The curvatures of three-dimensional surface formed by flexible rolling are implemented through transverse bending deformation and longitudinal non-uniform elongation deformation.

3) The simulation result of the forming force is agreed with the test result. The correctness of the model has been verified. The simulation method is suitable for calculating the forming force of three-dimensional surface sheet metal parts with complex shape in flexible rolling.

\section{Acknowledgements}

The authors appreciate the support of the National Natural Science Foundation of China (No. 51275202) and the continuing encouragement of the program.

\section{References}

[1] D.S. Shim, D.Y. Yang, K.H. Kim, S.W. Chung and M.S. Han: International Journal of Machine Tools Manufacture, Vol. 50 (2010) No.2, p.214-218.

[2] Z.Y. Cai, M. Z. Li and Y.W. Lan: Journal of Materials Processing Technology, Vol. 212 (2012) No.1, p.120-127.

[3] M.Z. Li, Z.Y. Cai, R.J. Li, Y.W. Lan and N.J. Qiu: Joural of Mechnical Engineering, Vol. 48 (2012) No.14, p.44-49. (In Chinese)

[4] X.Y. Duan: Theoretical Foundation of Metal Pressure Processing (Metallurgical Industry Press, China 2004), p.203-221. (In Chinese) 